\title{
Effects of Metformin on Insulin Resistance after Injury in the Rat
}

\author{
K. N. Frayn \\ Experimental Pathology of Trauma Section, MRC Toxicology Unit, Medical Research Council Laboratories, Carshalton, Surrey, U. K.
}

\begin{abstract}
Summary. Hyperglycaemia and insulin resistance occur after injury. The effects of the antidiabetic biguanide metformin in injured rats have been studied in order to elucidate the cause of these effects. Metfor$\min (120 \mathrm{mg} / \mathrm{kg} \mathrm{S}$. C.) produced a significant hypoglycaemic effect after a $20 \%$ dorsal scald but did not affect the blood glucose concentration in non-injured rats. The hypoglycaemic effect did not result from increased insulin secretion. It was associated with a reduction in liver glycogen and an increase in blood lactate concentrations, suggesting that the drug acted by promoting peripheral glucose utilization. This was confirmed by measuring the clearance rate coefficient of $\left[5-{ }^{3} \mathrm{H}\right]$ glucose. This rate coefficient was significantly increased by metformin treatment $(140 \mathrm{mg} / \mathrm{kg} \mathrm{S}$. C.) in scalded rats, although it was not affected in non-injured rats. Intravenous glucose tolerance in scalded rats was not improved, probably because of the increased lactate concentration. Metformin (120-160 mg/kg) also produced a hypoglycaemic effect in rats after a 4 hrs period of bilateral hind-limb ischaemia, suggesting that similar metabolic changes occur after these two types of injury.
\end{abstract}

Key words: Scald injury, ischaemic injury, biguanide, metformin, insulin resistance, glucose utilization, blood glucose, blood lactate, liver glycogen.

The acute metabolic response to injury in man and other animals includes a rise in the blood glucose concentration due both to mobilization of glycogen stores and to impairment of peripheral glucose utilization. Although the latter may result in part from suppression of insulin release [2, 47] impairment of peripheral sensitivity to insulin is also involved [10, $15,30]$. This insulin resistance is the major cause of the impairment of glucose utilization following a nonlethal $20 \%$ dorsal scald injury in the rat [15]. The injured rat is thus in a state of hyperglycaemia with insulin resistance, which suggests a similarity to experimental diabetes.

It was therefore of interest to determine whether hypoglycaemic drugs used in the treatment of diabetes might be effective in reducing injury-induced hyperglycaemia, since this might help in elucidating the cause of the insulin resistance produced by injury. The hypoglycaemic biguanide metformin was chosen since it promotes glucose uptake by rat muscle in conditions in which this is impaired [16]. In the present study some of the metabolic effects of metformin in injured rats have been investigated.

\section{Materials and Methods}

\section{Rats}

The rats used were male Porton-Wistar albinos, fed on M. R. C. diet $41 \mathrm{~B}$ and kept at $20^{\circ} \mathrm{C}$ ambient temperature with $12 \mathrm{hrs}$ of light per day from $07.00 \mathrm{hr}$. All experiments were performed at $20^{\circ} \mathrm{C}$. Rats to be injured weighed $246 \mathrm{~g}$ mean (range 235-267 g) and others $236 \mathrm{~g}$ mean (range 205-264 g). There were no significant differences in weight between metformintreated groups and their controls. For serial sampling a cannula was inserted under ether anaesthesia into a jugular vein [20] at least 4 days (median 7 days) before the experiment. Injury consisted either of a full-thickness dorsal scald to $20 \%$ of the body surface area, produced between $10.00 \mathrm{hr}$ and $12.30 \mathrm{hr}$ by partial immersion in water at $83{ }^{\circ} \mathrm{C}$ for 30 seconds, during a period (about 3-4 min) of ether anaesthesia [5], or of a $4 \mathrm{hrs}$ period of bilateral hind-limb ischaemia induced by application of tourniquets [36] from about 10.00 hr. Injections of metformin solutions or saline $(\mathrm{NaCl}$ 
$0.9 \%$ ), each $1 \mathrm{ml} / \mathrm{kg}$, were given subcutaneously (S. C.) immediately after scalding or at the time of removal of the tourniquets. Non-injured rats for serial sampling experiments were given a short period of ether anaesthesia (about $2 \mathrm{~min}$ ) while an initial blood sample was taken if required, metformin solution or saline $(1 \mathrm{ml} / \mathrm{kg} \mathrm{S}$. C.) injected, and the rat placed in a restraining cage.

In single sampling experiments rats were decapitated and blood collected in heparinized beakers. For serial sampling rats were given heparin ( 375 IU I. V.) before the experiment. Samples were withdrawn through the jugular vein cannula and an equal volume of saline replaced. Intravenous injections were given through a cannula inserted into a lateral tail vein at the time of injury or control anaesthesia.

For intravenous glucose tolerance tests rats were injected with glucose $[1 \mathrm{~g} / \mathrm{kg} \mathrm{I}$. V. as $50 \%(\mathrm{w} / \mathrm{v})$ solution] about $2-2.5 \mathrm{hrs}$ after scalding.

The rate of irreversible disposal of glucose was estimated by the method of Heath and Corney [26]. About 1.5-2 hrs after scalding or control anaesthesia a tracer amount of $\left[5-{ }^{3} \mathrm{H}\right]$ glucose (about $36 \mu \mathrm{Ci}$ in 0.2 $\mathrm{ml} \mathrm{I}$. V.) was injected. Four blood samples were taken from each rat close to the optimal sampling times [27] as judged from the first few experiments. For injured rats these times were 5, 30, 60 and $180 \mathrm{~min}$ (salinetreated) or 3,10,26 and $72 \mathrm{~min}$ (metformin-treated); for all non-injured rats they were $3,15,30$ and $95 \mathrm{~min}$. Calculations were based on the quantities of glucose label per $\mathrm{ml}$ of blood, instead of those in the total blood volume per $100 \mathrm{~g}$ body weight as in the original method. In injured rats the mean blood glucose concentrations during the period of experiment remained steady within experimental error (Table 1 ). The clearance rate coefficient, $\mathrm{k}$ [ml whole blood. $\mathrm{min}^{-1}$. $(100$ $\left.\mathrm{g})^{-1}\right]$, was assumed to remain constant during the experiment and calculated using equation (4.7) of Heath and Barton [25] with $M=1$. The rate of glucose utilization was calculated as the product of $k$ and the mean blood glucose concentration in each rat and is therefore a mean figure over the experimental period. Since the changes in blood glucose concentration during the experiment were so small, however, alternative methods of calculation do not affect the general conclusions reached. In non-injured rats the blood glucose followed the pattern described by Heath and Corney [26], rising and then falling to a minimum at the third sampling time, and 'end' rate coefficients and rates were calculated using their equations (4) and (5) with $\mathrm{n}=1$.

\section{Reagents}

Metformin hydrochloride was supplied by Rona Laboratories Ltd., Hitchin. Doses of metformin refer to the hydrochloride. Reagents for glucose and lactate assays were purchased in kit form from The Boehringer Corporation (London) Ltd. Reagents for insulin assay were as described previously [15] together with rabbit anti-guinea-pig globulin (RD 18) from Wellcome Reagents Ltd., Beckenham. D- $\left[5-{ }^{3} \mathrm{H}\right]$ glucose (TRK 290; specific activity $1.0 \mathrm{Ci} / \mathrm{mmol}$ ) was purchased from The Radiochemical Centre, Amersham. Resins used in determination of glucose specific radioactivity were as follows. Zerolit resins were purchased from B. D. H. Chemicals Ltd., Poole. Zerolit 325 cation exchange, $14-52$ mesh, was treated with $2 \mathrm{M} \mathrm{HCl}$ for 2 hours and washed with deionized water to $\mathrm{pH}$ 5-6. Zerolit MIP anion exchange, 14-52 mesh, was treated with $2 \mathrm{M} \mathrm{NaOH}$ for 2 hours and washed to $\mathrm{pH} 7$. These were then mixed $(1: 1$ by volume). AG $2-\mathrm{X} 8$ anion exchange resin, 200-400 mesh, chloride form, was purchased from V. A. Howe and Co. Ltd., London, and used as supplied.

\section{Analytical Methods}

Whole blood glucose and lactate concentrations were measured with hexokinase [38] and lactate dehydrogenase [29] respectively. Plasma insulin concentrations were measured in duplicate $50 \mu$ l samples with a

Table 1. Blood glucose concentrations $(\mathrm{mM})$ during estimation of irreversible disposal rate of glucose in rats

\begin{tabular}{|c|c|c|c|c|c|}
\hline & & \multicolumn{4}{|l|}{ Sample No. } \\
\hline & & 1 & 2 & 3 & 4 \\
\hline \multirow[t]{2}{*}{ Injured } & Controls (10) & $8.02 \pm 0.37$ & $8.78 \pm 0.46$ & $8.95 \pm 0.52$ & $7.90 \pm 0.63$ \\
\hline & Metformin-treated (10) & $5.87 \pm 0.55$ & $5.89 \pm 0.62$ & $5.74 \pm 0.63$ & $5.26 \pm 0.68$ \\
\hline \multirow[t]{2}{*}{ Non-injured } & Controls (8) & $6.33 \pm 0.18$ & $6.62 \pm 0.17$ & $5.98 \pm 0.11$ & $6.18 \pm 0.21$ \\
\hline & Metformin-treated (7) & $5.81 \pm 0.28$ & $6.23 \pm 0.22$ & $5.48 \pm 0.22$ & $6.18 \pm 0.21$ \\
\hline
\end{tabular}

Rats were injected with saline (controls) or metformin $(140 \mathrm{mg} / \mathrm{kg} \mathrm{s}$. c.) immediately after production of a $20 \%$ dorsal scald under ether anaesthesia (injured) or during brief ether anaesthesia (non-injured). $\left[5-{ }^{3} \mathrm{H}\right] \mathrm{Glucose}$ was injected I. V. 1.5-2 hrs later and four samples taken from each rat at times given in the text. Results are means \pm SEM; numbers of rats are given in parentheses. In injured rats no between-samples differences are significant $(P>0.1)$ within either group, but at each sampling time the blood glucose concentration is significantly lower $(\mathrm{P}<0.01)$ in the metformin-treated group than in their controls. In non-injured rats, both treated and control, the blood glucose concentrations fell significantly between samples 2 and $3(P<0.05)$. The blood glucose concentration in the metformin-treated non-injured rats was not significantly lower than in their controls at any sampling time $(P>0.05)$. 
double-antibody radioimmunoassay based on that of Morgan and Lazarow [34]. Liver glycogen was measured as glucose with the hexokinase method after ethanol precipitation and acid hydrolysis [21]. Haematocrit values were corrected for entrained plasma [24].

Glucose specific radioactivity was determined as follows $[24,28]$. Blood samples $(200 \mu \mathrm{l})$ were deproteinized [41] and $1.0 \mathrm{ml}$ of supernatant deionized by passage through a column $(110 \times 4 \mathrm{~mm})$ of the mixed Zerolit resins. After washing the column with $3 \mathrm{ml}$ deionized water the eluate was weighed and $0.5 \mathrm{ml}$ used for estimation of the blood glucose concentration. One drop of acetic acid was added to the remainder before evaporation to near dryness at $45^{\circ} \mathrm{C}$ under a stream of $\mathrm{N}_{2}$. The residue, in about $200 \mu \mathrm{l}$ of water, was streaked on to Whatman $3 \mathrm{MM}$ chromatography paper and developed at $24^{\circ} \mathrm{C}$ for $16-21 \mathrm{~h}$ with water - formic acid - 2-methylpropan-2-ol - butan-2-one (15:15:40:30 by volume). After drying the outer edges were removed and sprayed with $\mathrm{AgNO}_{3}$ in acetone followed by ethanolic $\mathrm{NaOH}$ to locate the glucose. The glucose band was cut out just within its leading edge to avoid an unidentified labelled contaminant. It was eluted with deionized water (about 2.5 $\mathrm{ml})$ through a column $(40 \times 3 \mathrm{~mm})$ of AG 2-X8 anion-exchange resin. One $\mathrm{ml}$ was taken for counting of radioactivity in $10 \mathrm{ml}$ Insta-Gel (Packard Instrument Company, Inc., Downers Grove, Ill., U.S.A.) and duplicate $0.5 \mathrm{ml}$ samples for determination of glucose concentration.

\section{Statistical Methods}

Differences between means have been compared using the t-test except when samples to be compared differed significantly in variance when non-parametric methods were used. All methods were as described by Snedecor and Cochran [40].

\section{Results}

\section{Effects of Metformin on Blood Glucose and Plasma Insulin Concentrations}

Blood glucose and plasma insulin concentrations were followed in serial samples from both non-injured and scalded rats given a single dose of metformin (Figs. 1 and 2). The control rats, both non-injured and scalded, were injected with saline. After 6 hrs the rats were given access to food and the $24 \mathrm{hrs}$ sample was obtained by decapitation.

1. Non-Injured Rats. Metformin had no effect on either the blood glucose or the plasma insulin concentration (Fig. 1). The blood glucose concentration remained steady after the first sample in which it was probably elevated by handling and by the brief anaesthesia [8]. The plasma insulin concentrations fell during the day and were still low after $24 \mathrm{hrs}$. They have been expressed as percentages of the initial concentration in each rat since the initial values were very vari-

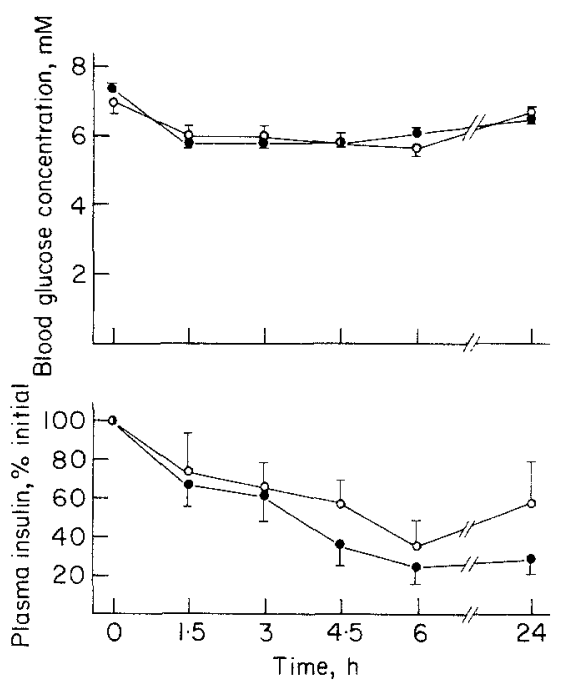

Fig. 1. Effect of metformin on blood glucose and plasma insulin concentrations in non-injured rats. Saline (controls) or metformin $(120 \mathrm{mg} / \mathrm{kg})$ was injected s. c. immediately after withdrawing the first sample under ether anaesthesia. Points show means \pm SEM; $\mathrm{n}=5$ (controls; open points) $\mathrm{n}=6$ (metformin-treated; solid points). Differences between control and metformin-treated rats were not significant at any time
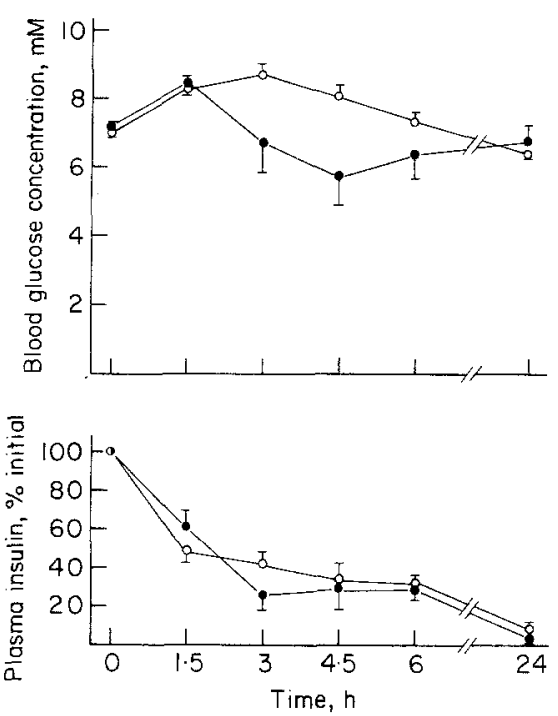

Fig. 2. Effect of metformin on blood glucose and plasma insulin concentrations in scalded rats. Saline (controls) or metformin (120 $\mathrm{mg} / \mathrm{kg}$ ) was injected s. c. immediately after producing a $20 \%$ dorsal scald injury under ether anaesthesia. The first sample was taken immediately before scalding. Points show means \pm SEM; $n=7$ (controls; open points), $n=6$ (metformin-treated; solid points). The blood glucose concentration was significantly lower $(\mathrm{P}<0.05)$ in the metformin-treated group than in the controls at 3 and $4.5 \mathrm{hrs}$. Differences in plasma insulin concentrations were not significant at any time 
able; mean values $(\mu \mathrm{U} / \mathrm{ml}, \pm \mathrm{SEM})$ were: controls, $10.5 \pm 2.4$; metformin-treated, $9.8 \pm 2.0$.

2. Scalded Rats (Fig. 2). In the control (i. e. saline-injected) scalded rats the blood glucose concentration rose to remain fairly steady from $1.5-4.5 \mathrm{hrs}$ after injury. Metformin produced a significant hypoglycaemic effect, although the response to metformin was variable. The between-rats variance in blood glucose concentration was significantly greater in the metformin-treated rats than in the controls at 3, 4.5 and 6 hrs after scalding $(\mathrm{P}<0.025$ by F-test $)$. Metformin did not affect the plasma insulin concentrations which again fell and were very low after $24 \mathrm{hrs}$. The mean initial plasma insulin concentrations $(\mu \mathrm{U} / \mathrm{ml}, \pm$ SEM) were: controls, $10.9 \pm 1.0$; metformin-treated, $13.6 \pm 1.4$.

\section{Effects of Metformin in Various Doses in Scalded Rats}

Blood glucose and lactate and liver glycogen concentrations were measured in scalded rats treated with metformin (0-200 mg/kg S. C.) and killed $3 \mathrm{hrs}( \pm 1$ min) later. Although the dose-response relationship was obscured by variability in the response to metformin, a fall in blood glucose concentration was associated with a rise in blood lactate concentration (Fig. 3) and a fall in liver glycogen (Fig. 4). In the four of these scalded rats given saline only the mean liver glycogen concentration was $2.90 \pm 0.19(\mathrm{mg} / 100 \mathrm{mg}$,

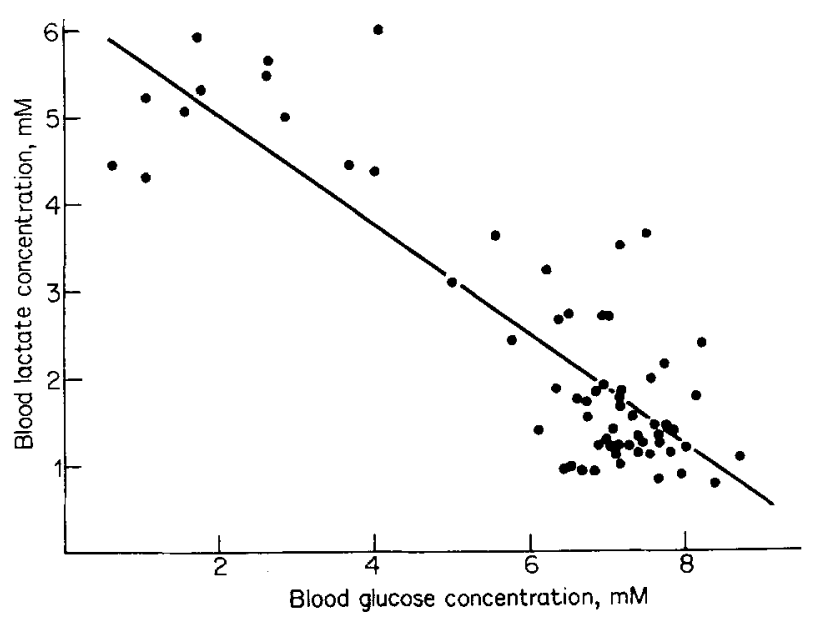

Fig. 3. Relationship between concentrations in blood of glucose and lactate in rats treated with metformin $(0-200 \mathrm{mg} / \mathrm{kg} \mathrm{s}$. c.) immediately after producing a $20 \%$ dorsal scald. The rats were killed for these measurements 3 hrs later. Each point represents the result from a single rat. The line shows the regression of lactate on glucose. The correlation between blood glucose and lactate concentrations is highly significant $(\mathrm{r}=-0.86, \mathrm{P}<0.001)$ \pm SEM); this is at least an order of magnitude greater than that found after $24 \mathrm{hrs}$ starvation in the rat (e. g. ref. $43 ; 0.2-0.01 \mathrm{mg} / 100 \mathrm{mg}$ ).

In addition a hypoglycaemic response was associated with a rise in great-vessel haematocrit $(r=$ $-0.52, \mathrm{P}<0.001, \mathrm{n}=63$ ), although this was only a slight effect, the regression line for haematocrit $(y ; \%)$ on blood glucose concentration $(\mathrm{x} ; \mathrm{mM})$ being: $\mathrm{y}=-0.757 \mathrm{x}+55.3$.

\section{Effect of Metformin on Intravenous Glucose Toler- ance in Scalded Rats}

Intravenous glucose tolerance tests were performed on scalded rats injected with either saline (controls) or metformin. The blood glucose concentrations, followed by serial sampling, are shown in Fig. 5 .

The blood glucose concentration was significantly lower $(P \leqslant 0.05)$ before and at all times after glucose injection in the metformin-treated rats. The fractional rate of fall of blood glucose concentration in each rat $\left(\mathrm{K} ; \% \cdot \mathrm{min}^{-1}\right)[13]$ was estimated over the linear part of the curve (2-10 min after injection). Despite the hypoglycaemic effect of metformin treatment $\mathrm{K}$ was not altered $(\mathrm{K}$; means $\pm \mathrm{SEM}, \mathrm{n}=7$ : controls, $4.6 \pm$ 0.6 ; metformin-treated, $5.5 \pm 0.9$ ). Although this method of calculating $\mathrm{K}$ seems preferable $[11,39]$ to that based on the increment above the pre-injection level [4], $\mathrm{K}$ calculated on the latter basis was similarly

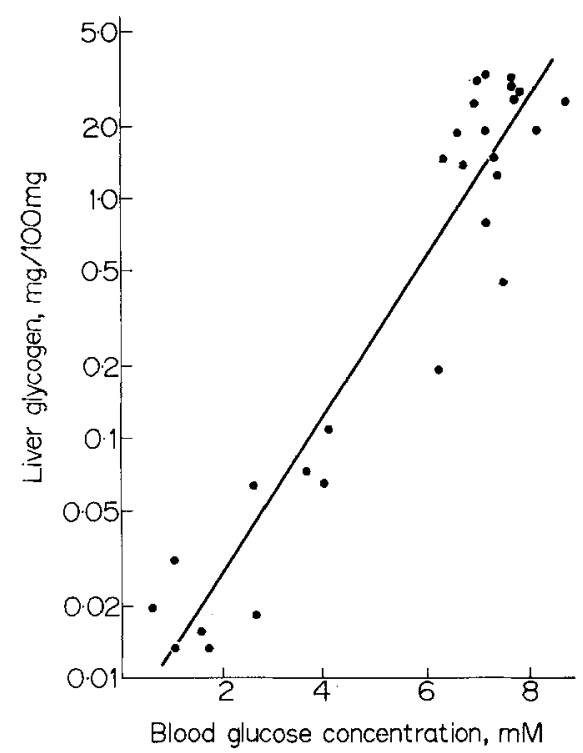

Fig. 4. Relationship between concentrations of glucose in blood and glycogen in liver in rats treated with metformin $(0-200 \mathrm{mg} / \mathrm{kg} \mathrm{s} . \mathrm{c}$.) immediately after producing a $20 \%$ dorsal scald. The rats were killed for these measurements $3 \mathrm{hrs} \mathrm{later.} \mathrm{Each} \mathrm{point} \mathrm{represents} \mathrm{the}$ result from a single rat. Liver glycogen is plotted on a logarithmic scale. The line shows the regression of $\log$ (glycogen) on glucose. The correlation between blood glucose and log(liver glycogen) is highly significant $(\mathrm{r}=0.95, \mathrm{P}<0.001)$ 


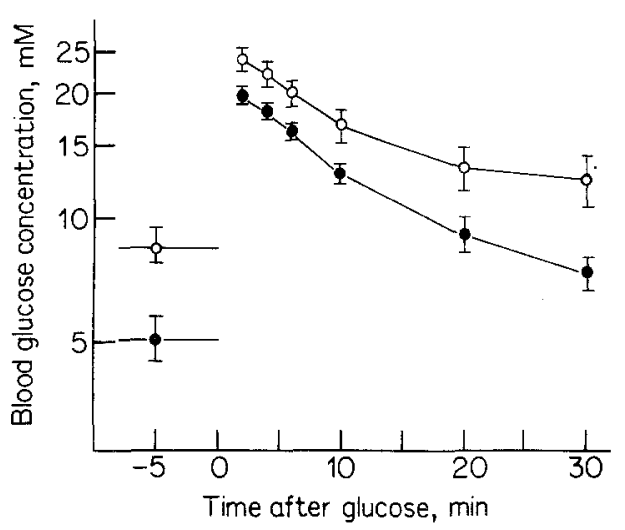

Fig. 5. Effects of metformin $(120 \mathrm{mg} / \mathrm{kg} \mathrm{s}$. c.) on intravenous glucose tolerance in scalded rats. Rats were injected with saline (controls; open points) or metformin (solid points) immediately after producing a $20 \%$ dorsal scald and glucose $(1 \mathrm{~g} / \mathrm{kg} \mathrm{I}$. V.) was injected 2 hrs later. Points show means \pm SEM; $n=7$ in each group. The blood glucose concentration was significantly lower $(\mathrm{P} \leqslant 0.05)$ at all times in the metformin-treated group than in the controls, but metformin had no effect on the $\mathrm{K}$-value

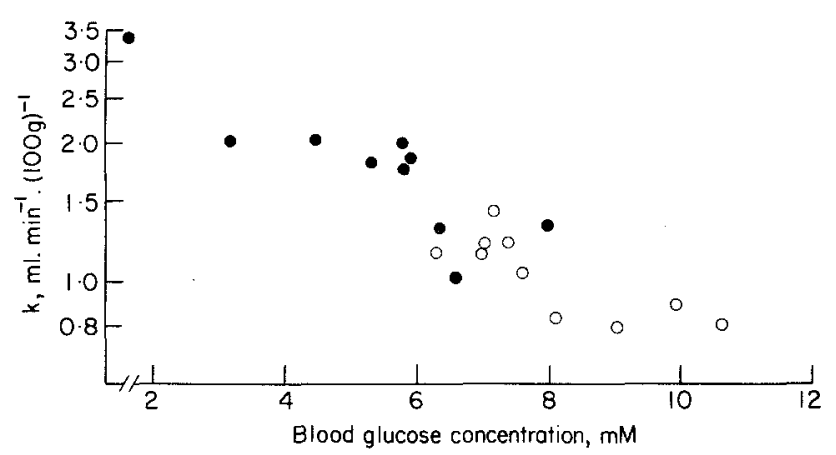

Fig. 7. Relationship between clearance rate $(k)$ of $\left[5-{ }^{3} \mathrm{H}\right]$ glucose and blood glucose concentration in scalded rats injected with metformin (140 mg/kg s. c.) (solid points) or with saline (open points). Each point shows the result from a single rat. $\mathrm{k}$ is plotted on a logarithmic scale. The correlation between blood glucose and $\log \mathrm{k}$ over all rats is highly significant $(\mathrm{r}=-0.91, \mathrm{P}<0.001, \mathrm{n}=20)$

unaffected by metformin treatment (controls, $8.2 \pm$ 1.0 ; metformin-treated, $8.7 \pm 1.6 \% \cdot \mathrm{min}^{-1}$ ). In further sections $\mathrm{K}$ refers to that calculated on the basis of the total blood glucose concentration.

The blood lactate concentration, estimated $30 \mathrm{~min}$ after glucose injection, was not significantly different in the two groups (controls, $2.7 \pm 0.5$; metformintreated, $2.6 \pm 0.4 \mathrm{mM}$ : means $\pm \mathrm{SEM}, \mathrm{n}=7$ ). There was a striking negative correlation between $K$ and the blood lactate concentration in the metformin-treated group only (Fig. 6).

\section{Effect of Metformin on Glucose Utilization}

The rate coefficient and absolute rate of irreversible disposal of glucose were determined using $\left[5-{ }^{3} \mathrm{H}\right]$ glucose in both non-injured and scalded rats injected

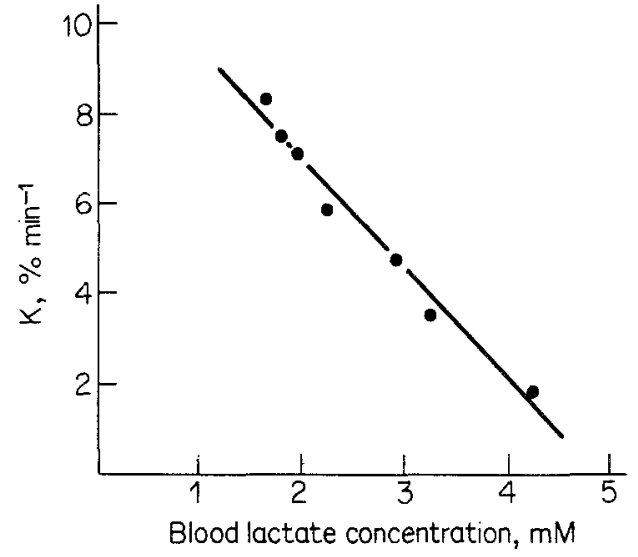

Fig. 6. Relationship between intravenous glucose tolerance $(\mathrm{K})$ and blood lactate concentration in rats treated with metformin (120 $\mathrm{mg} / \mathrm{kg} \mathrm{s}$. c.) immediately after producing a $20 \%$ dorsal scald. Each point represents the result from a single rat. The line shows the regression of $\mathbf{K}$ on blood lactate. The correlation between $\mathrm{K}$ and blood lactate concentration is highly significant $(r=-0.988$, $\mathrm{P}<<0.001$ )

with either metformin $(140 \mathrm{mg} / \mathrm{kg}$ ) or saline (controls) (Tables 1 and 2).

In non-injured rats there was a slight tendency towards lower blood glucose concentrations with this dose of metformin, although this was not significant at any sampling time. Neither the clearance rate coefficient (k) nor the absolute disposal rate were significantly affected by metformin.

In metformin-treated injured rats, however, the mean blood glucose concentration over the period of study was significantly lower and $\mathrm{k}$ significantly higher than in their controls, although the mean absolute disposal rate was again not significantly different. $\mathrm{k}$ showed a significant negative correlation with the mean blood glucose concentration both in each treatment group and in this group as a whole (Fig. 7).

The plasma insulin concentrations, measured in the last sample from all injured rats except the first two in each treatment group, showed a positive correlation with the mean blood glucose concentration in the metformin-treated group $(\mathrm{r}=0.80, \mathrm{P}<0.02)$ and in the whole group $(\mathrm{r}=0.71, \mathrm{P}<0.002)$.

\section{Effect of Metformin on Blood Glucose Concentration after Ischaemic Injury}

After a 4 hrs period of bilateral hind-limb ischaemia rats were injected with saline or metformin and killed by decapitation $3 \mathrm{hrs}$ ( $\pm 1 \mathrm{~min}$ ) later, the time at which the peak blood glucose concentration is normally reached [42]. Metformin in doses greater than 80 $\mathrm{mg} / \mathrm{kg}$ produced a significant dose-related reduction in blood glucose concentration with no change in great-vessel haematocrit (Table 3). 
Table 2. Effects of metformin on irreversible disposal of glucose in rats

\begin{tabular}{|c|c|c|c|c|c|}
\hline & & $\pi$ & $\begin{array}{l}\text { Blood glucose } \\
\text { concentration } \\
\mathrm{mM}\end{array}$ & $\begin{array}{l}\text { Clearance rate } \\
\text { coefficient } \\
\text { ml. } \text { min }^{-1} \cdot(100 \mathrm{~g})^{-1}\end{array}$ & $\begin{array}{l}\text { Absolute } \\
\text { disposal rate } \\
\mu \text { mol. } \min ^{-1} \cdot(100 \mathrm{~g})^{-1}\end{array}$ \\
\hline \multirow[t]{2}{*}{ Injured } & Controls & 10 & $8.4 \pm 0.4$ & $1.06 \pm 0.07$ & $8.7 \pm 0.3$ \\
\hline & Metformin-treated & 10 & $5.7 \pm 0.6^{\mathrm{a}}$ & $1.85 \pm 0.21^{\mathrm{a}}$ & $9.6 \pm 0.6$ \\
\hline \multirow[t]{2}{*}{ Non-injured } & Controls & 8 & $6.2 \pm 0.2$ & $1.27 \pm 0.04$ & $7.9 \pm 0.5$ \\
\hline & Metformin-treated & 7 & $6.2 \pm 0.2$ & $1.33 \pm 0.11$ & $8.1 \pm 0.6$ \\
\hline
\end{tabular}

${ }^{a}$ Significantly different from controls $(P<0.002)$

Experimental details were as described in Table 1 and methods of calculation as in the text. For reasons given in the text 'mean' results over the period of experiment are shown for injured rats and 'end' results for non-injured. Results are means \pm SEM.

Table 3. Effects of metformin on blood glucose concentration and on great-vessel haematocrit in rats injured by 4 hrs period of bilateral hind-limb ischaemia

\begin{tabular}{rrrr}
\hline $\begin{array}{l}\text { Dose } \\
(\mathrm{mg} / \mathrm{kg})\end{array}$ & Glucose & Haematocrit & $\mathrm{n}$ \\
\hline 0 & $100 \pm 5$ & $100 \pm 5$ & 5 \\
80 & $84 \pm 12$ & $102 \pm 7$ & 3 \\
120 & $82 \pm 4^{\mathrm{a}}$ & $98 \pm 5$ & 3 \\
160 & $17.3 \pm 0.5^{\mathrm{b}}$ & $103 \pm 5$ & 3 \\
\hline
\end{tabular}

a Significantly different from controls $(\mathrm{P}<0.05)$

b Significantly different from controls $(\mathrm{P}<<0.001)$

Metformin (or saline in controls) was injected s. c. at the end of the period of ischaemia and rats decapitated 3 hrs later. Results (mean $\pm \mathrm{SEM}$ ) are expressed as percentages of mean control value. Mean control values were: glucose, $10.3 \mathrm{mM}$; haematocrit 57.8 .

\section{Discussion}

The metabolic changes following the scald and ischaemic injuries in the rat have been extensively studied and many features of the response are well established. The hyperglycaemia following these injuries results mainly from the rapid mobilization of liver and muscle glycogen [23, 42], probably with no great increase in the rate of hepatic gluconeogenesis $[7,42]$. These changes occur under the influence of adrenaline [44] and probably glucagon [23, 26] and are to some extent abolished by prior medullectomy $[42,43]$. The blood glucose concentration remains high for several hours after injury since the rate of peripheral glucose utilization fails to rise to match the increased concentration [26]. After the scald injury this impairment of glucose utilization is known to be due to insulin resistance rather than to suppression of insulin release [15].

There are thus several possible explanations for the hypoglycaemic effect of metformin in the injured rat, some of which may be readily discounted. Metformin did not act simply by reducing the severity of the injury since the raised haematocrit values typical of these non-haemorrhagic injuries were not lowered by hypoglycaemic doses of metformin. After scald injury metformin in fact caused a slight increase in haematocrit, probably representing further loss of plasma volume secondary to the hypoglycaemia. Biguanides impair intestinal absorption of glucose [6, 32], but this action is unlikely to have been important in the substantially post-absorptive rats used in this study. The hypoglycaemic effect was not due to inhibition of the hepatic glycogenolysis since it was associated with a further reduction in liver glycogen concentration (Fig. 4) to levels well below those of untreated scalded rats. This reduction in liver glycogen was therefore probably a normal response to the metformin-induced hypoglycaemia.

The increase in blood lactate concentration (Fig. 3) suggested that metformin might act either by inhibition of hepatic gluconeogenesis from this substrate, or by stimulation of glucose uptake by muscle, with consequent lactate production. These possibilities were investigated by means of glucose tolerance tests and by direct measurement of the glucose disposal rate.

In diabetic patients intravenous glucose tolerance is improved by treatment with metformin $[17,31]$ and this has been taken as evidence for stimulation of peripheral glucose uptake, but no significant change in $\mathrm{K}$-value was observed in the present study (Fig. 5). The intravenous glucose tolerance test is, however, unsatisfactory for investigating glucose utilization since, apart from introducing a gross metabolic disturbance, it depends on the balance between utilization and production of glucose. The lack of effect of metformin, despite a significant hypoglycaemic effect, may be related to the highly significant inverse correlation in the treated rats between blood lactate concentration and K-value (Fig. 6). Since the rate of hepatic gluconeogenesis from lactate in the rat is proportional to the plasma lactate concentration over this range [1] any elevation by metformin of the blood lactate concentration will increase the rate of hepatic glucose output, thus counteracting the stimulation of peripheral glucose uptake. This finding therefore suggests that hepatic gluconeogenesis from lactate was 
not inhibited by metformin under these conditions. Although the biguanides can inhibit hepatic gluconeogenesis in various species $[14,45]$ the rat liver is not as sensitive to this effect as that of other species such as guinea-pig [3], and Polacek and Ouart have recently shown [35] that the hypoglycaemic effect of phenformin in the rat in vivo is independent of hepatic effects.

Glucose utilization was estimated directly from the irreversible disposal rate of $\left[5-{ }^{3} \mathrm{H}\right]$ glucose. These studies were made at times such that the blood glucose concentrations in the injured rats were fairly steady in both control and metformin-treated groups (Table 1). The clearance rate coefficient, $k$, was significantly greater in the metformin-treated injured rats than in their controls (Fig. 7), although the absolute rate of glucose utilization was not significantly different. This suggests that metformin primarily increased $\mathrm{k}$, thus lowering the blood glucose concentration to a level at which the utilization rate again balanced the glucose production rate. This implies that the rate of hepatic glucose production was unaltered by metformin. The stimulation of glucose utilization did not, however, result from increased insulin secretion. The plasma insulin concentration was not significantly altered by a hypoglycaemic dose of metformin (Fig. 2) and in the $\left[5-{ }^{3} \mathrm{H}\right]$ glucose disposal studies there was a positive correlation between blood glucose and plasma insulin levels, suggesting that the latter were being controlled by the former rather than vice versa. The hypoglycaemic effect of the biguanides in man similarly does not involve increased insulin secretion $[9,22]$.

Metformin is thus able to overcome the insulin resistance which occurs after this scald injury at a dose which is without significant effect on the concentration or turnover of blood glucose in the normal rat. Although the cause of this insulin resistance is unknown it has been suggested [15] that it may be similar to the insensitivity to insulin of glucose uptake by muscle in experimental diabetes, and the present results would be consistent with this suggestion. The biguanides lower the blood glucose concentration in diabetes at doses which have no hypoglycaemic effect in normally-fed non-diabetic man [33] or rat [46], and metformin in vitro stimulates glucose uptake into muscle from alloxan-diabetic rats in concentrations which have no effect on normal muscle [16]. The stimulation by metformin of glucose uptake into muscle in vitro is probably an intracellular effect rather than an action on the cell membrane, since it is seen only when intracellular utilization of glucose, rather than its membrane transport, is the rate-limiting step in glucose uptake $[16,18]$. If the action of metformin after injury is similar to its action in diabetes, this would suggest that the insulin resistance caused by injury in the rat is the result of an intracellular impairment of glucose utilization in muscle, rather than of a direct impairment of membrane transport or its regulation by insulin, as has been suggested in man [19]. Insulin resistance of this nature in muscle should be demonstrable in vitro as is the case in experimental diabetes [16], and this has been observed after haemorrhagic shock in the rat [12] and rabbit [37]. The scald and ischaemic injuries in the rat produce similar effects on glucose utilization [26] and the finding that metformin also produces a hypoglycaemic effect after ischaemic injury adds support to the idea that these two types of injury result in a common basic metabolic disturbance.

The present study thus adds to our understanding of the pathophysiology of injury by suggesting a mechanism for the insulin resistance and impairment of glucose utilization which occur after injury. However, these effects probably represent a defence mechanism ensuring adequate energy supplies for insulin-independent tissues such as the central nervous system, and it is not suggested that overcoming them with metformin would necessarily be beneficial.

Acknowledgements. I should like to thank Rona Laboratories Ltd., Hitchin, for helpful information and for the metformin hydrochloride. The Boots Company Ltd., Nottingham, and Wellcome Reagents Ltd., Beckenham, donated some of the reagents used for the radioimmunoassay. I am grateful to Dr. D. F. Heath for advice on the glucose disposal experiments, and to B. J. Passingham and Paula F. Maycock for technical assistance.

\section{References}

1. Aikawa, T., Matsutaka, H., Takezawa, K., Ishikawa, E.: Gluconeogenesis and amino acid metabolism. 1. Comparison of various precursors for hepatic gluconeogenesis in vivo. Biochim. biophys. Acta (Amst.) 279, 234-244 (1972)

2. Allison, S. P., Hinton, P., Chamberlain, M. J.: Intravenous glucose-tolerance, insulin, and free-fatty-acid levels in burned patients. Lancet 1968 II, 1113-1116

3. Altschuld, R. A., Kruger, F. A.: Inhibition of hepatic gluconeogenesis in guinea pig by phenformin. Ann. N. Y. Acad. Sci. 148, 612-622 (1968)

4. Amatuzio, D. S., Stutzman, F. L., Vanderbilt, M. J., Nesbitt, S.: Interpretation of the rapid intravenous glucose tolerance test in normal individuals and in mild diabetes mellitus. J. clin. Invest. 32, 428-435 (1953)

5. Arturson, G.: Pathophysiological aspects of the burn syndrome. Acta chir. scand. (Suppl.) 274 (1961)

6. Arvanitakis, C., Lorenzsonn, V., Olsen, W. A.: Phenformin-induced alterations of small intestinal function and mitochondrial structure in man. J. Lab. clin. Med. 82, 195-200 (1973)

7. Ashby, M. M., Heath, D. F., Stoner, H. B.: A quantitative study of carbohydrate metabolism in the normal and injured rat. J. Physiol. (Lond.) 179, 193-237 (1965) 
8. Besch, E. L., Chou, B. J.: Physiological responses to blood collection methods in rats. Proc. Soc. exp. Biol. (N. Y.) 138, 1019-1021 (1971)

9. Boshell, B. R., Roddam, R. F., McAdams, G. L.: Effects of phenformin on insulin reserve and release. Ann. N. Y. Acad. Sci. 148, 756-767 (1968)

10. Butterfield, W. J. H.: Hypoglycaemic effect of dimercaprol (BAL) in burned patients and in diabetics with insulin-resistant hyperglycaemia. Lancet 1955 I, 489-490

11. Butterfield, W. J. H., Abrams, M. E., Whichelow, M. J.: The 25-g intravenous glucose tolerance test: a critical appraisal. Metabolism 20, 255-265 (1971)

12. Chaudry, I. H., Sayeed, M. M., Baue, A. E.: The effect of insulin on glucose uptake in soleus muscle during hemorrhagic shock. Canad. J. Physiol. Pharmacol. 53, 67-73 (1975)

13. Conard, V., Franckson, J. R. M., Bastenie, P. A., Kestens, J., Kovacs, L.: Étude critique du triangle d'hyperglycémie intraveineux chez l'homme normal et détermination d'un "coefficient d'assimilation glucidique". Arch. int. Pharmacodyn. 93, 277-292 (1953)

14. Connon, J. J.: A differential action of phenformin in normal and diabetic rat livers. Diabetologia 9, 47-49 (1973)

15. Frayn, K. N.: Effects of burn injury on insulin secretion and on sensitivity to insulin in the rat in vivo. Europ. J. clin. Invest. 5 , 331-337 (1975)

16. Frayn, K. N., Adnitt, P. I.: Effects of metformin on glucose uptake by isolated diaphragm from normal and diabetic rats. Biochem. Pharmacol. 21, 3153-3162 (1972)

17. Frayn, K. N., Adnitt, P. I., Turner, P.: The hypoglycaemic action of metformin. Postgrad. med. J. 47, 777-780 (1971)

18. Frayn, K. N., Adnitt, P.I., Turner, P.: The use of human skeletal muscle in vitro for biochemical and pharmacological studies of glucose uptake. Clin. Sci. 44, 55-62 (1973)

19. Giddings, A. E. B.: The control of plasma glucose in the surgical patient. Brit. J. Surg. 61, 787-792 (1974)

20. Ginsburg, M., Heller, H.: The antidiuretic assay of vasopressin by intravenous injection into unanaesthetized rats. J. Endocr. 9, 267-273 (1953)

21. Good, C. A., Kramer, H., Somogyi, M.: The determination of glycogen. J. biol. Chem. 100, 485-491 (1933)

22. Grodsky, G. M., Karam, J. H., Pavlatos, F. C., Forsham, P. H.: Reduction by phenformin of excessive insulin levels after glucose loading in obese and diabetic subjects. Metabolism 12, 278-286 (1963)

23. Heath, D. F.: Liver metabolism after injury. In: Neurohumoral and metabolic aspects of injury (eds. A. G. B. Kovách, H. B. Stoner, J. J. Spitzer), pp. 271-276. New York: Plenum Press 1973

24. Heath, D. F.: The effect of scald injury upon the distribution of glucose between red cells and plasma and upon the turnover of glucose in red cells in the rat. Brit. J. exp. Path. 54, 359-367 (1973)

25. Heath, D. F., Barton, R. N.: The design of experiments using isotopes for the determination of the rates of disposal of bloodborne substrates in vivo with special reference to glucose, ketone bodies, free fatty acids and proteins. Biochem. J. 136, 503-518 (1973)

26. Heath, D. F., Corney, P. L.: The effects of starvation, environmental temperature and injury on the rate of disposal of glucose by the rat. Biochem. J. 136, 519-530 (1973)

27. Heath, D. F., Cunningham, V. J.: The calculation of errors and the choice of sampling times in the determination of irreversible disposal rates in vivo by isotope experiments. Biochem. J. 152, 417-420 (1975)

28. Heath, D. F., Rose, J. G.: The distribution of glucose and $\left[{ }^{14} \mathrm{C}\right]$ glucose between erythrocytes and plasma in the rat. Biochem. J. 112, 373-377 (1969)
29. Hohorst, H.-J.: L-(+)-lactate. Determination with lactic dehydrogenase and DPN. In: Methods of enzymatic analysis (ed. H.-U. Bergmeyer), pp. 266-270. New York and London: Academic Press 1965

30. Howard, J. M.: Studies of the absorption and metabolism of glucose following injury. The systemic response to injury. Ann. Surg. 141, 321-326 (1955)

31. Irsigler, K.: Effect of metformin (dimethylbiguanide) on glucose utilization and body weight. Dtsch. med. Wschr. 95, 2169-2174 (1970)

32. Lorch, E.: Inhibition of intestinal absorption and improvement of oral glucose tolerance by biguanides in the normal and in the streptozotocin-diabetic rat. Diabetologia 7, 195-203 (1971)

33. Madison, L. L., Unger, R. H.: Effect of phenformin on peripheral glucose utilization in human diabetic and nondiabetic subjects. Diabetes 9, 202-206 (1960)

34. Morgan, C. R., Lazarow, A.: Immunoassay of insulin: Two antibody system. Plasma insulin levels of normal, subdiabetic and diabetic rats. Diabetes 12, 115-126 (1963)

35. Polacek, I., Ouart, J.: Effect of phenformin in hyperglycemic rats. Diabetes 23, 25-28 (1974)

36. Rosenthal, S. M.: Experimental chemotherapy of burns and shock. iv. Production of traumatic shock in mice. v. Therapy with mouse serum and sodium salts. Publ. Hlth. Rep. (Wash.) 58, 1429-1436 (1943)

37. Ryan, N. T., George, B. C., Egdahl, D. H., Egdahl, R. H.: Chronic tissue insulin resistance following hemorrhagic shock. Ann. Surg. 180, 402-407 (1974)

38. Schmidt, F. H. Die enzymatische Bestimmung von Glucose und Fructose nebeneinander. Klin. Wschr. 39, 1244-1247 (1961)

39. Silcock, D. H., Hadden, D. R., Neill, D. W.: Computer analysis of intravenous glucose-tolerance tests. Diabetologia 8 , 301-304 (1972)

40. Snedecor, G. W., Cochran, W. G.: Statistical methods, 6th edition. Ames: Iowa State University Press 1967

41. Somogyi, M.: A method for the preparation of blood filtrates for the determination of sugar. J. biol. Chem. 86, 655-663 (1930)

42. Stoner, H. B.: Studies on the mechanism of shock. The quantitative aspects of glycogen metabolism after limb ischaemia in the rat. Brit. J. exp. Path. 39, 635-651 (1958)

43. Stoner, H. B., Threlfall, C. J., Green, H. N.: Studies on the mechanism of shock. Carbohydrate metabolism in nucleotide and ischaemic shock. Brit. J. exp. Path. 33, 131-156 (1952)

44. Stoner, H. B., Westerholm, B.: The secretion of adrenaline and noradrenaline in $20^{\circ} \mathrm{C}$ and $3{ }^{\circ} \mathrm{C}$ acclimated rats injured by limb ischemia. Acta physiol. scand. 75, 552-564 (1969)

45. Toews, C. J., Kyner, J. L., Connon, J. J., Cahill, G. F.: The effect of phenformin on gluconeogenesis in isolated perfused rat liver. Diabetes 19, 368 (1970)

46. Ungar, G., Freedman, L., Shapiro, S. L.: Pharmacological studies of a new oral hypoglycemic drug. Proc. Soc. exp. Biol. (N. Y.) 95, 190-192 (1957)

47. Vigaš, M., Németh, Š., Jurčovičová, J.: The mechanism of trauma-induced inhibition of insulin release. Horm. Metab. Res. 5, 322-324 (1973)

Received: July 2, 1975, and in revised form: November 4, 1975

K. N. Frayn, Ph. D.

Experimental Pathology of Trauma Section

MRC Toxicology Unit

Medical Research Council Laboratories

Woodmansterne Road

Carshalton, Surrey SM5 4EF

U. K. 